\title{
Innovation Landscape within Family Services Integration: Evidence from Australia
}

\author{
Philip Thomas \\ University of New England \\ E-Mail: philip.thomas@une.edu.au \\ Sujana Adapa \\ University of New England \\ E-Mail: sadapa2@une.edu.au \\ Barbara King Joyce \\ University of Melbourne \\ E-Mail: kingbj@unimelb.edu.au
}

\begin{abstract}
The aim of this research is to explore the utility of collaborative innovation landscape within the government Family and Community Services (FACS) organisation in Australia. Exploring the presence or absence of the collaborative innovation landscape within public sector organisations is important, as the organisation's objectives combined with the effective management of people working within the organisation define the productivity and efficiency measures of an organisation. The collaborative innovation landscape in FACS is investigated in line with the identified gaps in the existing literature by exploring the structure and function of the organisation, working relationships, team-based interactions and respondents' perceptions of the prevailing working environment. Qualitative in-depth interviews and Social Network Analysis (SNA) techniques were used in the present study to analyse the data obtained from the respondents. Respondents were employed within the divisions of FACS government organisation operating in Tamworth in regional Australia. The results obtained indicated that the respondents' lack of interdivision familiarity poses additional challenges in terms of understanding the nature of work, clarity of role and subsequent engagement with clients and personnel across divisions
\end{abstract}


identified within FACS government organisation. The results obtained from the SNA indicated the presence of reciprocal relationships of the respondents with the other respondents working within their divisions. The findings suggest that collaborative type of innovation landscape is at a nascent stage within the FACS government organisation, and efforts need to be directed to strengthen the public sector innovations in Australia.

Keywords: Collaborative Innovation Landscape, FACS, Vision, Participative Safety, Task Orientation, Support for Innovation, Regional Australia

\section{INTRODUCTION}

Innovations within the organisations have been extensively studied. It is undeniable that innovations are regarded as a key to success in an ever-changing and competitively fierce environment (Sorensen and Torfing, 2012). Evidently, the extent of engagement in embedding innovations in practice varies depending upon the type of sector and the nature of business. For example, private businesses rely heavily on innovations as a source of differentiation to improve product offerings, reduce costs and open-up new markets. On the contrary, small and medium sized businesses tend to form strategic alliances with each other to remain and maintain a competitive position (Sorensen and Torfing, 2011). The innovations existing within the public sector seem to be limited and largely neglected by the academic researchers. The reasons for the less popularity of the public sector innovations include the complexity associated with the organisations operating within the sector, the uniqueness of the services offered by these organisations, ever-changing bureaucratic policies and prevailing red tape related mechanisms (Sorensen and Torfing, 2012).

The four popular types of innovations include product innovation, process innovation, marketing innovation, and organisational innovation (OECD, 2005). Product and process type of innovations align with the technological advancements. Non-technological innovations relate to the marketing and organisational innovations (OECD, 2005). This study considers only the organisational type of innovations. Organisational innovation in practice involves several elements that focus on the best practice, collaboration, retention, decision-making and relationship management (Camison and Villar-Lopez, 2014). The identification of organisational innovation as a distinct and separate type of innovation is relatively new, and it has gained attention only in the last decade (Hamel, 2006). The knowledge surrounding the outcomes of the implementation of the organisational innovations remains limited in the existing literature (Damanpour and Aravind, 2012). 
Organisations are typically viewed in terms of their people, organisational objectives and distinct organisational structure. Irrespective of the structure of organisation, effective management of people within an organisation is critical to foster productivity and efficiency of an organisation (Liao and Chi-Chuan, 2010). In the existing research, several inter and intra organisational dimensions are identified to be relevant in fostering organisational innovations (Armbruster et al., 2008). When promoting a favourable environment for an organisation, in order to increase its efficiency, intra organisational dimensions, such as organisation culture and climate evidently are the most important variables (Cotton, 2003). The new structures and procedures outside the organisation contribute to the inter-organisational dimension (Battisti and Stoneman, 2010).

It is important that organisations function with clarity in the context of increasing competition as well as in an environment where frequent changes are expected (Heinrich, Lynn and Milward, 2009). Organisation's climate is important to reduce ambiguity and conflict and foster sustainable relationships amongst the employees (Koppenjan and Klijn, 2004). Poorly defined organisational culture and climate will have an adverse effect on the employees working within an organisation. Lack of appropriate management practices within an organisation will result in poor communication, decreased support for innovation and lack of clarity in outlining various organisational objectives (Agranoff, 2007). By way of implementing these measures within an organisation, employees take the responsibility and overcome the decision latitude in terms of low participation and lack of involvement in the decision-making process (Cotton and Hart, 2004).

Supportive organisation climate combined with sustainable people management practices will enhance the productivity and efficiency of the organisation through team culture and employee morale (Agranoff, 2007). The team level predictors that contribute to the organisational innovations have been largely overlooked (Hulsheger et al., 2009). Specifically the researchers have largely neglected the effect of the meso-level factors, such as those related to the work teams or team-based variables that largely contribute to the collaborative innovation or creative profile of the organisations (Shalley et al., 2004). It is important for the survival of the organisations to critically focus on developing an innovative landscape within their organisations through better informed team interventions.

Team culture is important to overcome the social and/or physical isolation as well as the interpersonal conflicts. Moreover, effective team climate fosters role clarity, professional development, goal alignment, and clear understanding of the 
organisation's objectives (Cotton, 2004). Employee morale is important for enhancing the employee's job satisfaction and wellbeing. The performance of the employees will be made visible through their behavioural outcomes, such as task performance and meeting with the core operational demands of the organisation.

The innovations within government organisations are regarded to be highly bureaucratic, fostering closed ways of innovating (Bommert, 2010). Such type of closed innovations are criticised because they are not directed towards solving any type of policy challenges. Academic research calls for public sector to focus on new ways of radical type of quality and quantity innovations aimed at solving the emerging and persistent problems (Harris and Albury, 2009). Considering that the existing research within the government sector is limited and lacks solutions to address the challenges faced by the government sector, this research study proposes the new form of collaborative innovation as an alternative to meet the needs of the government sector.

Collaborative innovation brings together organisations and individuals in order to discover, develop, and implement ideas (Eggers and Singh, 2009). Nambisan (2008) identifies that the collaborative approach enhances the problem solving abilities of the government organisations, fosters resource utilisation and increases creativity of external networks and communities. Evidently, the principal feature associated with the collaborative type of innovation is to foster the innovation landscape within the government organisations by way of encouraging the various actors to identify their innovation assets and active participation (Bommert, 2010). In light of this discussion, the productive and efficiency gains of Australian government organisations have been under-researched. Therefore, this research sets out to explore the collaborative innovation landscape within an Australian government organisation with an aim to provide an answer to the extant research calls made earlier by the academics and researchers working in the area of public sector innovations. This research study aims to identify the most important context-specific determinants in order to define the collaborative innovation landscape for a government organisation operating in regional Australia.

\section{LITERATURE REVIEW}

Organisational innovations are often associated with performance, at least in theory. This resource-based view attests the importance of the organisation's resources and capabilities in creating a competitive advantage and associated superior performance (Yang, Marlow and Lu, 2009). The individuals' capabilities within an organisation are linked to the productivity and efficiency measures as well as to the 
working objectives and strategic goals outlined by the organisation (Ortega, 2010). The contemporary literature on organisational innovations focuses on the division of work, presence of team climate, sustainability of relationships, and type of interactions rather than relying only on the productivity and efficiency gains (OECD, 2005). The existing literature related to the organisational innovations in public sector is limited (Armbruster et al., 2008) and addresses the importance of organisational innovations in the overall organisational performance (Walker, Damanpour and Devece, 2010). Literature related to the organisational innovations is associated with theories related to the knowledge-based view, organisational learning and network theories (Crossan and Apaydin, 2010) with limited success.

Central to the organisational innovations literature is the widely quoted Hackman's (1987) IPO (input-process-output) model of team performance (Ilgen et al., 2005). Team input variables relate to the size of the team, team composition, team longevity, job relevance, team diversity and task interdependence in promoting innovation and creativity in organisations (West, 2002). Based on the interactionist theory of innovation (Woodman et al., 1993), team process-related variables include vision, participative safety, task orientation and support for innovation. Thus, the existing theoretical frameworks based on the concept of organisational innovations seem to lack coherence.

The objectives of an organisation and the structure of the organisation depend on the people working in that organisation. Therefore, the people element plays a central role within an organisation and defines an organisation's strategic intent, purpose and objectives (Jimenez-Jimenez and Sanz-Valle, 2011). Within an organisation, people occupy different positions, forming a structural hierarchy within organisations. The most common classification of people within an organisation is three tiered, involving front-line staff, middle management and upper senior management (Choi, 2007). Organisations may also have vertical or horizontal hierarchy-based models that correlate with flat or tiered type of structures.

Irrespective of the structure and size of the organisation, effective management of people and maintenance of sensible relationships (Hansen and Levine, 2009) are crucial for successful business and the viability of the organisation itself, and they may not necessarily reflect the formal or understood organisational structure (Choi et al., 2009). In the light of this discussion, it is important to understand the nature of working relationship within the organisation context by identifying the existing professional work contacts amongst individuals, since these relationships have potential to create a more integrated workplace, fostering innovation (Bell, 2007), developing a desired 
team culture (Howell and Shea, 2006), increasing the productivity of the employees and enhancing the efficiency gains of the organisation (Choi and Chang, 2009).

The overall productivity and efficiency of any organisation is critically dependent on human and social factors (Boehm et al., 2000). Organisational climate is defined as '...the shared perception of organisational procedures, practices and policies' (Reichers $\&$ Schneider, 1990). In the present research project, the concept of shared perceptions is measured at the team level as a team climate (Acuna et al., 2008). Anderson and West (1998) defined team climate as shared perceptions that refer to the 'proximal work group'. The extant literature highlights several psychometric tests and questionnaires that measure a range of service and team climate dimensions. The Team Selection Inventory (TSI) and the Team Climate Inventory (TCI) are identified as the most populous psychometric inventories for assessing team climate preferences and perceptions (Acuna et al., 2008).

Much attention has been given to the importance of innovation in work environments that are increasingly complex, dynamic, and competitive (Mathieu et al., 2008). It is recognized that collaborative effort plays an important part in achieving outcomes that are aimed at satisfying stakeholders' (clients, customers, and institutional) goals (Baer and Frese, 2003). Contemporary work teams generally comprise various stakeholders, including individuals from the government, industry, and community who are often from very different contextual (work social and institutional) backgrounds. The significant challenge for these workplace collaborations is to create and maintain a homogenous environment that encourages individual and collective entrepreneurial action in order to achieve desired goals and outcomes (Cladwell and O'Reilly, 2003).

Given the gaps in the existing literature on the theoretical base of organisational innovations, the present study takes an integrated theoretical framework by combining organisational literature, networking theory, and resource-based views. By investigating the team interactions, working relationships, and work environment, this research aims to explore the capacity of work teams to innovate with an aim to achieve service provision integration within a government workplace context through collaborative type of innovation landscape. By exploring the engagement of the individuals working in a government organisation with various stakeholders, this preliminary research aimed to explore the collaborative innovation landscape of a government service-providing organisation operating in Tamworth, Australia. The information in this study will provide certain practical implications to the individuals and the organisations aligned with the Australian public sector. 
Collaborative type of innovation landscape within an organisation focuses on wiping out the formal bureaucratic boundaries and matching the existing resources with the innovative and creative capabilities of the external networks and communities (Bommert, 2010). As organisations tend to operate in a unique and diverse manner, the innovation potential in public sector is often overlooked due to the existence of formality and associated bureaucratic type of decision-making. Effective coordination of government organisations is essential for achieving the public value (Bommert, 2010). Hence, combining the networked approach with the existing resources and the organisational objectives is envisaged to foster a much needed collaborative innovative landscape within public sector organisations.

The factors that are envisaged to be critical in determining effective team functioning (West and Anderson, 1996) relate to several factors, including (1) organization's vision based on how clearly the team defines goals (Humphrey and Konrad, 2005); (2) participative safety based on how much trust the team members have to be part of a group (Anderson and West, 1998); (3) task orientation based on the effort of the team puts to achieve excellent outcomes (Acuna et al., 2008); (4) support for innovation based on the consent and support provided by the team to foster innovative ideas (Beck et al., 2001); and (5) possible interactions of the teams across divisions for better outcomes and collaborations (Acuna et al., 2008).

Organization' vision represents the team member's commitment to achieve the stated goals and organisation objectives (West and Anderson, 1996). The understanding of the organisation's objectives by the team members is critical. Clearly articulated goals will enhance the team members' efforts to achieve the organisation's stated goals and objectives (Rickards et al., 2001). Participative safety refers to the extent to which the team members are involved in the active decision-making within the organisations and to the extent to which the team members share the information in order to achieve the collective goals of innovative environment in the organisation (Edmondson, 1999). Participative safety also relates to the trust and support amongst the team members with an aim to encourage the team to focus on developing new ideas and enduring commitment for the success of the organisation (Burke et al. 2006). Focus on the participative safety variable will actually help team members communicate openly, with an intention to collaborate and cooperate to achieve organisational objectives that are mutually beneficial to the senior management and the team members (Tiwana and McLean, 2005).

Task orientation element pushes the team to the highest standards of performance by reflecting on the team's objectives, strategies, and procedures. During this process, 
teams are positively encouraged to evaluate each other's work in order to improve their effectiveness and outcomes (Somech, 2006). Continuous monitoring and regular feedback and execution of plans that align with the team and organisation's goals will foster team innovation within the organisation (Tjosvold et al., 2004). It is important to support innovation, as this allows the team members to take more risks and implement new ideas (King et al., 1991). Therefore, organisations need to support new ideas while immediate supervisors and managers need to focus on the implementation aspect (Shalley et al., 2004).

\section{METHODOLOGY}

The current investigation was carried out to understand the presence or absence of collative innovation landscape within NSW Department of Family and Community Service (FACS), which is a government organisation operating in regional Australia. This study defined the collaborative innovation landscape in terms of a multitude of attributes, such as organisational structure, network communications (interactions and directions), and workplace perception of the individuals working within FACS (West, 1990). FACS funded this study, the core objective of which was to identify the most important dimensions that foster collaborative innovation landscape within the three divisions of FACS.

FACS consists of three divisions, Ageing Disability and Home Care (ADHC), Community Services (CS), and Housing. Overall, nine in-depth interviews were carried out with the key personnel occupying critical managerial roles with the three divisions of FACS. The interview question protocol comprised three important sections. The first section included questions to gather demographic information from the respondents, such as the respondent's position, job role within his/her division, and the length of service in his/her current role. The remaining questions included in the first section gathered information about the respondents' interactions within their division, interactions with other divisions of FACS, and interactions outside FACS. The second section asked respondents about the nature of working relationships with other individuals in the divisions. Finally, the third section involved a series of questions that gathered the respondents' perceptions of the work environment and the prevailing team climate within FACS (Strating and Nieboer, 2009).

\section{Brief Background on FACS}

The government organisation FACS consists of eight divisions, i.e., Aboriginal Housing Office; Ageing, Disability and Home Care; Community Services; Housing NSW; Office for Ageing; Office for Carers; NSW Business link Pty Ltd; and Women 
NSW operating across Australia. However, the three divisions of FACS ADHC, CS, and Housing are instrumental in the provision of human services within NSW due to the unique nature of the services that these divisions offer to the client base.

ADHC provides support for aged and disabled individuals and their families through case management focused on client needs. ADHC's client base falls within the age range of 0-65 years, and its function is to access and provide services that cater for intellectual disability, community access support and home care. ADHC currently operates in teams consisting of case managers, an access manager, a speech pathologist, a behavioural therapist, an occupational therapist and a psychologist. Case managers may handle around 12 to 15 clients, which is often classified as an active caseload at any one time. Although caseloads run independently, peer support is available for the case managers and generally, case managers are aware of each other's clients as well as the unique clients' needs.

CS operations mainly include cases related to the child protection. CS division works with children at risk and children placed in an out of home care and focuses on strengthening families and implementing early intervention strategies. At the time of this research investigation, there were three child protection teams, each team consisting of five to six members. These teams consisted of two staff members dealing with the initial reporting process and four staff members dealing with the subsequent assessment of the case and safety issues associated with the client.

Housing division largely focuses on establishing tenancy and property care as well as on sustaining established tenancy. This includes dealing with rental or lease agreements, tenancy damage, unacceptable social behaviour, improper care of the property and overcrowding (in the form of additional occupants). Housing Division's role is complex and ongoing, with at least a quarter of the existing tenants having a case plan. The teams within the Housing Division, popularly known as tenancy and access teams, need to work with each other and other Housing teams within the region to offer satisfactory service to their client base (NSW Government FACS).

\section{Study Scope and the Interviewees}

In the current investigation, the investigators recruited the respondents to participate in in-depth interviews after which they asked them to complete the demographic questionnaire as well as questions assessing interactions and perceptions of the working environment. The respondents were recruited from ADHC, CS, and Housing Divisions operating under FACS in Tamworth located in the northern inland region of regional NSW. Tamworth was selected because it engaged in youth services research development within the regional NSW and conveniently, all offices of the 
three divisions of interest are located within the township. The researchers recruited the respondents through the assistance of the management and made the initial contact with the three divisions of FACS via telephone.

Three respondents from ADHC, four from the CS and two from the Housing divisions agreed to participate in the process of in-depth interviews and share their opinions and perceptions about the prevailing work environment and collaborative innovation with the researchers. The researchers were able to secure only nine interviews due to a major work place change occurring in the government organisations at the time of investigation. The contact details of the nine interviewees were provided to the research investigators from the top management of FACS, and the research investigators were not allowed to contact other individuals working within and across FACS divisions because of privacy and security concerns. Nevertheless, the researchers also found that the responses obtained from the interviewees started to converge into similar themes at that point of investigation. The length of service of the interviewees was between 2 and 7 years, and all interviewees were involved in the management of client services and/or case management. The interviews lasted 45 minutes to one hour, with an additional five to ten minutes required to fill out the short questionnaire. Most respondents in the current study were case managers with diverse experiences within their division and with at least two years of experience in their current role. Only two respondents indicated that they had been in their current role for less than 6 months ( 2 months and 4 months). However, these respondents indicated that they had relevant past experience within their divisions.

\section{Social Network Analysis (SNA)}

Social Network Analysis (SNA) is used to establish the importance of relationships among interacting units (commonly referred as nodes) by way of identifying and defining the linkages among these units (Scott, 2000). SNA is widely used to understand the social relationships among individuals and groups; therefore, it can enhance communication and communication efficiency and foster collaboration and innovation within and between groups that form networks. Network refers to individuals, teams, or organisations connected by set of ties, and social network refers to the individual ties that connect a pair of nodes.

Extant literature on SNA highlights predominantly two schools of thought. One school of thought emphasises that individuals can be differentiated by their membership into socially distinct groups or roles by focusing more on structure when interpreting behaviour. In contrast, the second school of thought views SNA as a tool for 
disseminating information, exerting influence, and even identifying the position of the individual in the overall pattern, thus focusing on both structure as well as the differences in actors' interpretations of behaviour (Hill and Dunbar, 2003). SNA is useful within the current investigation in that it facilitates the creation of the non-hierarchical formal and informal interactions based on actual exchanges and use of resources. This complements and contrasts the information that might be available within the existing formal or organised organisational structure, generally recognised as the operating structure to which an institution refers when making management decisions.

\section{Team Structure}

\section{RESULTS}

For the purpose of our investigation, the government organisation FACS was prominently identified by three divisions, that is, ADHC, CS, and Housing, rather than the outlined eight divisions due to the uniqueness of the services that these divisions offer to the clients. Through the examination of the function of the respondent's duties, we examined this structure, and from this enquiry, it became apparent that each of these divisions could be further classified into various sub-divisions. The sub-divisions emerged from information about groupings that existed around the nature of duties carried out by individuals on a day-to-day basis within the recognised three divisions of ADHC, CS, and Housing (Table 1). From the responses obtained through qualitative in-depth interviews, it became evident that ADHC had three sub-divisions that included Ageing, Disability, and Home Care; CS had two sub-divisions including Child Protection and Case Management; and Housing had two sub-divisions, namely Tenancy Management and Access Management (Figure 1). The Disability sub-division had recognised teams, operating as the Access Team, Accommodation and Respite, and Service Delivery and Planning.

Our study indicated that the respondents had a good intra-division understanding of the existence and function of the sub-divisions. However, there was little inter-division understanding of the sub-divisions and team structures, and they were not easily identified, specifically if the respondent was outside the existing division. It was noted that this situation would very likely pose a problem for clients wishing to access the services, particularly new clients that are likely to be unfamiliar with the services available or the service provision structure in place. In addition, it was noted that a lack of inter-division familiarity with the service provision structure might also pose additional challenges for service providers in terms of understanding the nature of the 
work, roles of the personnel, and the ease of identification and engagement with personnel across divisions.

\section{Working Objectives}

The responses obtained from the respondents indicated an alignment between team-based and division-based objectives in reference to achieving the desired outcomes. The verbatim comments from the respondents offer support to this observation (Table 2).

\section{Working Relationships}

Respondents were asked to describe the individuals with whom they would 'talk to' about clients who require services offered by a particular division and services offered other divisions, other departments, Non-Government Organisations (NGOs), and others. These questions also relate to the networking relationships enquiry presented and discussed in the next section.

Table 1 Respondents' Profile

\begin{tabular}{clll}
\hline Division & \multicolumn{1}{c}{ Respondents } & \multicolumn{1}{c}{ Job Role } & \multicolumn{1}{c}{$\begin{array}{c}\text { Length of Service in } \\
\text { Current Role }\end{array}$} \\
\hline \multirow{3}{*}{ ADHC } & Respondent \# 1 & Aboriginal Case Manager & 2 years \\
\cline { 2 - 4 } & Respondent \# 2 & Case manager & 2.5 years \\
\cline { 2 - 4 } & Respondent \# 3 & Case Manager & 4 years \\
\hline \multirow{2}{*}{ CS } & Respondent \# 4 & $\begin{array}{l}\text { Manager Casework Child } \\
\text { Protection }\end{array}$ & 3 years \\
\cline { 2 - 4 } & Respondent \# 5 & $\begin{array}{l}\text { Manager Casework Child } \\
\text { Protection }\end{array}$ & 6 years \\
\cline { 2 - 4 } & Respondent \# 6 & $\begin{array}{l}\text { Manager Client Services Home } \\
\text { Care }\end{array}$ & 7 years \\
\cline { 2 - 4 } & Respondent \# 7 & (Acting) Manager Casework & 2 months \\
\hline \multirow{2}{*}{ Housing } & Respondent \# 8 & Senior Client Service Officer & 4 months \\
\cline { 2 - 4 } & Respondent \# 9 & Tenancy Management & 2 years \\
\hline
\end{tabular}

The rationale for including this particular question was to identify the divisions that helped respondents carry out their day-to-day tasks easily. Although most respondents responded to this question, a few preferred not to provide any response. Declining to respond was taken as an indication that there was concern with the airing of view on this subject by some respondents. Respondents who preferred not to respond to this question indicated that the question addressed a sensitive topic. The 
respondents' comments suggested that they are more connected and comfortable working with their own divisions rather than across them. Table 3 presents the verbatim comments provided by the respondents in response to the working relationships within and across divisions.

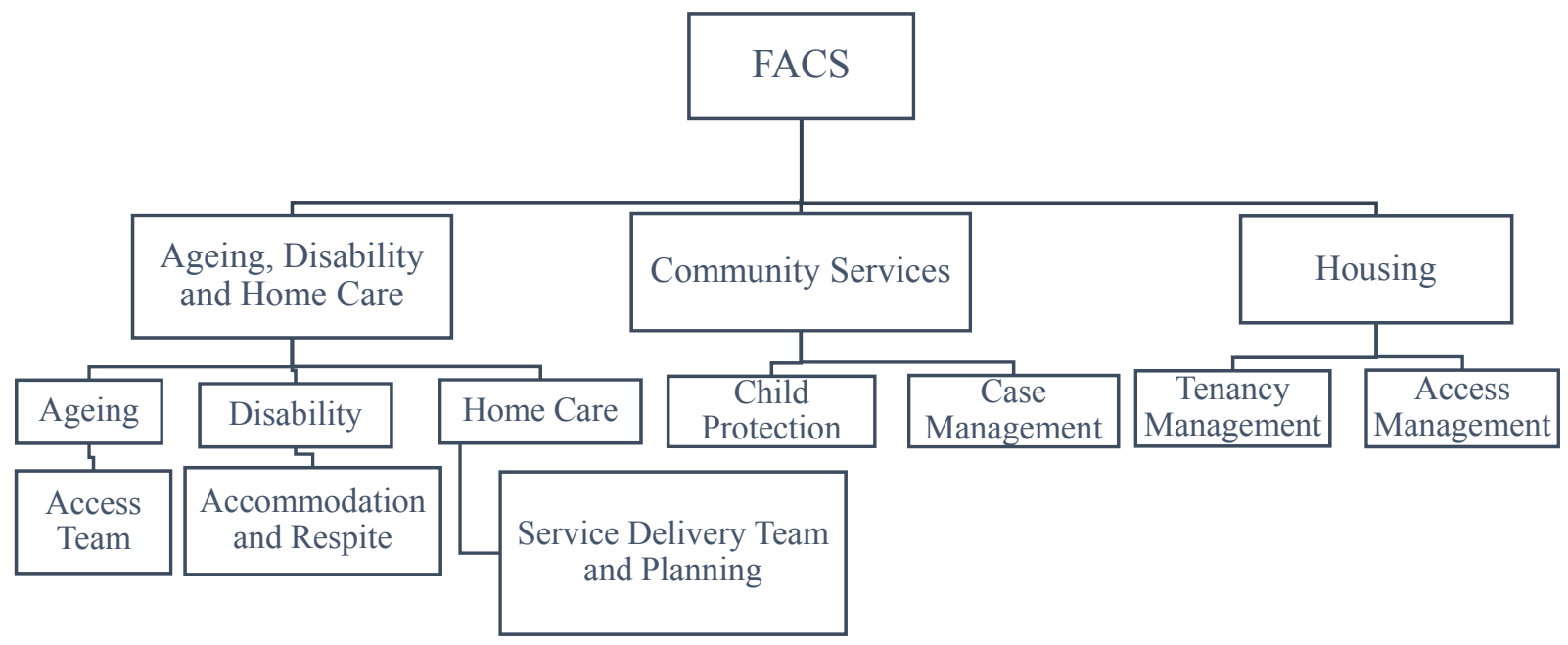

Figure 1 FACS (Tamworth) Organisation Structure

Table 2 Respondents' Perceptions towards Working Objectives

\begin{tabular}{ll}
\hline Respondent \# 1 & $\begin{array}{l}\text { "Yes! The main focus is on broader planning, good case management } \\
\text { and better outcomes." }\end{array}$ \\
\hline "Mespondent \# 2 & $\begin{array}{l}\text { "Major emphasis is on identifying creative ways of meeting needs of } \\
\text { person and not to fit them. Also focus on originality or individuality in } \\
\text { a way identifying what they want and what they don't want." }\end{array}$ \\
\hline "Aim to support individuals with disabilities and their families. Often \\
coaching, mentoring and supervisory responsibilities are identified to \\
be part of the team."
\end{tabular}

The respondents were also asked to indicate the divisions with which they did not feel comfortable working. Difficulties in working within divisions and across divisions were observed in participants' responses. In particular, difficulties were noted working with $\mathrm{ADHC}$, and the respondents highlighted the problems associated with the roles of the staff and the transitioning phase of the staff. Table 4 presents the verbatim 
comments provided by the respondents in regards to the difficulties associated in working within and across divisions.

Table 3 Respondents' Perceptions towards Working Relationships

\begin{tabular}{ll}
\hline Respondent \# 1 & $\begin{array}{l}\text { "All of them! Mostly prefer the way how ADHC as a team operates and } \\
\text { like the increased coordination." }\end{array}$ \\
\hline Respondent \# 2 & "Prefers to work as part of the team in ADHC." \\
\hline Respondent \# 3 & "Happy with the ADHC team." \\
Respondent \# 4 & $\begin{array}{l}\text { "Have regular meetings with ADHC and looks for balance between } \\
\text { government and non-government organisations in retrieving } \\
\text { information based on the client's needs." }\end{array}$ \\
\hline Respondent \# 9 & "Prefers to work with NGOs, support agencies and Centre link." \\
\hline Respondent \# 7 & $\begin{array}{l}\text { "Housing and health that largely depends on the outcomes of the } \\
\text { clients." }\end{array}$ \\
\hline
\end{tabular}

Table 4 Respondents' Perceptions towards Difficult Working Relationships

\begin{tabular}{ll}
\hline Respondent \# 1 & "One particular area of concern is working with health sector." \\
\hline Respondent \# 3 & $\begin{array}{l}\text { "Extremely hard to contact Guardianship Tribunal due to difficult } \\
\text { nature of work." }\end{array}$ \\
\hline Respondent \# 4 & "Do not work with Housing on a broader scale." \\
\hline Respondent \# 7 & "With ADHC! Problems with the delineation of roles." \\
\hline Respondent \# 9 & $\begin{array}{l}\text { "ADHC! Very demanding and want the things to be done now as most } \\
\text { of the staff are in the transition phase." }\end{array}$ \\
\hline
\end{tabular}

It was noted that to achieve collaborative innovation landscape and improved integration within the FACS government organisation, it might be useful to further investigate the issues within and across division interactions. The following section focuses on the working relationship that the respondents' value by identifying individuals with whom they have talked to as part of their job and day-to-day activities over the past twelve months within their division or other divisions across FACS department. Questions inquired about the respondents' professional contact with the identified individual and respondents' awareness of the skills, knowledge, effectiveness, and influence of the identified individual.

The responses obtained from the respondents across all three divisions operating under FACS department indicated that the individuals have the most professional contact with their immediate managers in carrying out their daily job related tasks. Most 
respondents also highlighted that they liaise with the immediate managers more than once a week. Respondents from the CS Division indicated the reciprocal nature of the relationship, as the identified immediate manager also contacts employees frequently for information, allowing for mutual exchange and free flow of information. Most respondents across the divisions also indicated that they were aware of the skills and knowledge levels of the previously identified individual who was very effective in helping them arrive at critical solutions to problems at hand. The also agreed that the identified individuals were generally very influential to somewhat influential as immediate managers within their divisions.

\section{Social Network Analysis}

The information obtained about the interactions among the respondents concerning the task of managing efficiency in providing high-end client services within their division, outside their division, and other government, and non-government organisations was analysed using Social Network Analysis (SNA). Names and roles of the contacts with whom the respondent liaises in order to carry out their work as well as the details related to the frequency of contact on a daily, weekly, monthly, or occasional basis were gathered by the researchers. The data was coded based on the types of interactions and organisations. The network diagrams presented here depict the interactions based on the organisation affiliation.

Figure 2: Network Diagram representing interactions between and within FACS Divisions - ADHC (Black dot), CS (White dot), and Housing (Brown dot). Arrows indicate the direction of interaction, numbers indicate individual contacts (ego contacts interviewed from FACS (v1-v9) and alters, contacts from interviews (all other numbered dots).

SNA allows a representation of the non-hierarchical, formal and informal interactions that might exist within a network. Acknowledging the constraints of the interactions existing in FACS between the respondents and their alters, within and across the three Divisions (Figure 2), all respondents except two from Housing appeared to be working in reciprocal relationships with the other respondents within their divisions with the exception of Housing. This finding is unclear, and it should be investigated in future studies. Recorded interactions indicate that overall, respondents interacted mostly within their Divisions (with an average of 6, 9, and 10 relationships per respondents within ADHC, CS, and Housing, respectively). On average, respondents had 2 relationships with people in other divisions. 


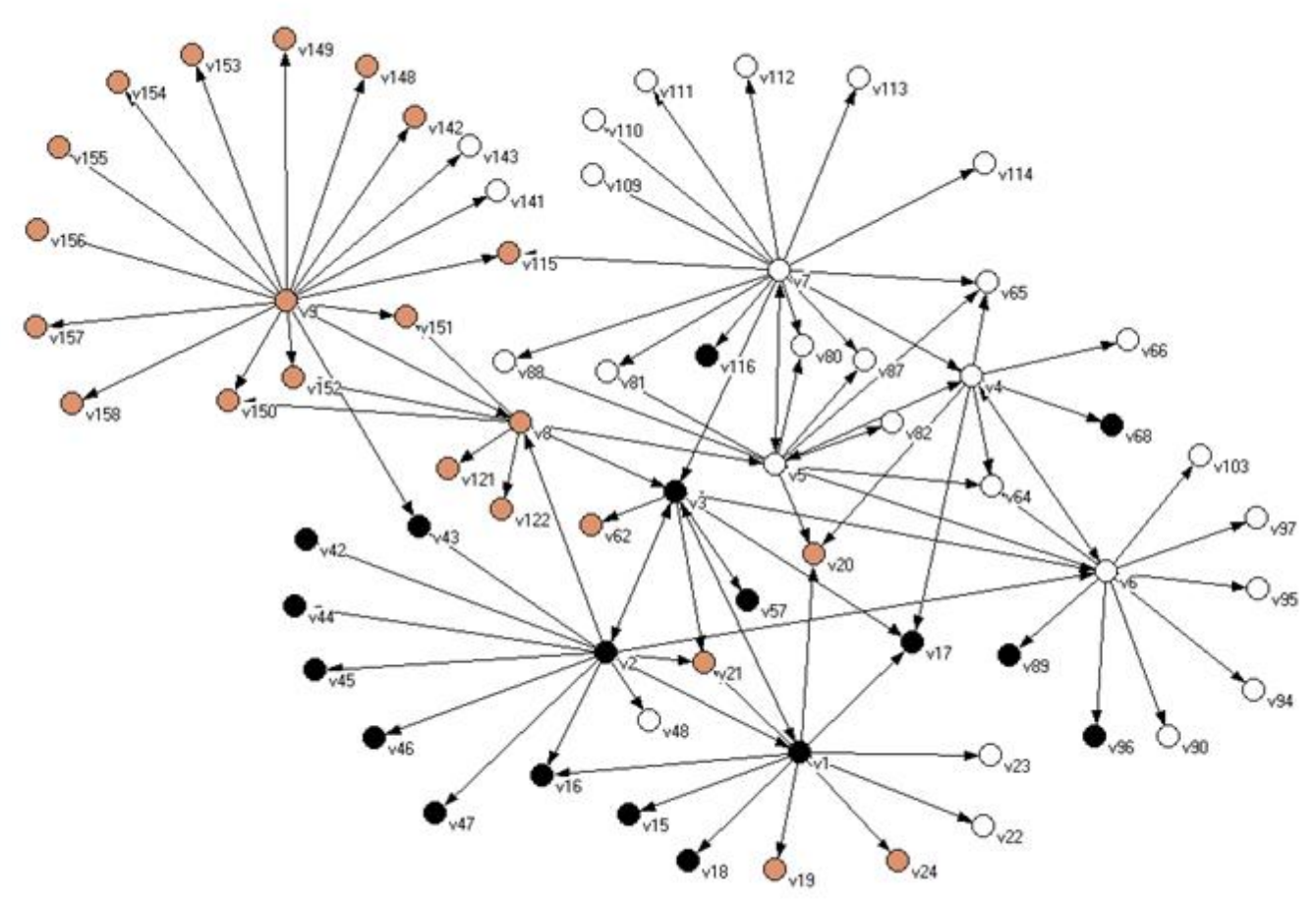

Figure 2 Interactions between and within FACS Divisions

It can be seen that one respondent (v3) who had mutual relationships with at least one respondent in each division, was identified as a key broker between divisions. This relationship pattern was unique, although other respondents appeared to have brokering (mutual) relationships with ADHC. A good example of the insight that can be gained from SNA investigation was that (with the exception of the relationship pattern of v3) a 'structural hole' between CS and Housing appeared to exist, which is likely to impede innovation and an integrated work effort.

It should be noted that the information compiled here should be interpreted within the constraints that the data set was very small and that there may be others in broker roles not revealed here. Additionally, some alters have overlapping relationships, meaning that they were informally connecting the divisions. If there were other connections that we did not observe in this study, these connections may be enabling information to pass between them that is not obvious here (i.e., not interviewed).

Figure 3: Network Diagram representing Interactions of FACS Divisions with other Government Organisations. ADHC (Black dot), CS (White dot), and Housing (Brown dot). Other government organisations (Pink dot), non-government organisations (Green dot), and others (Blue dot). 


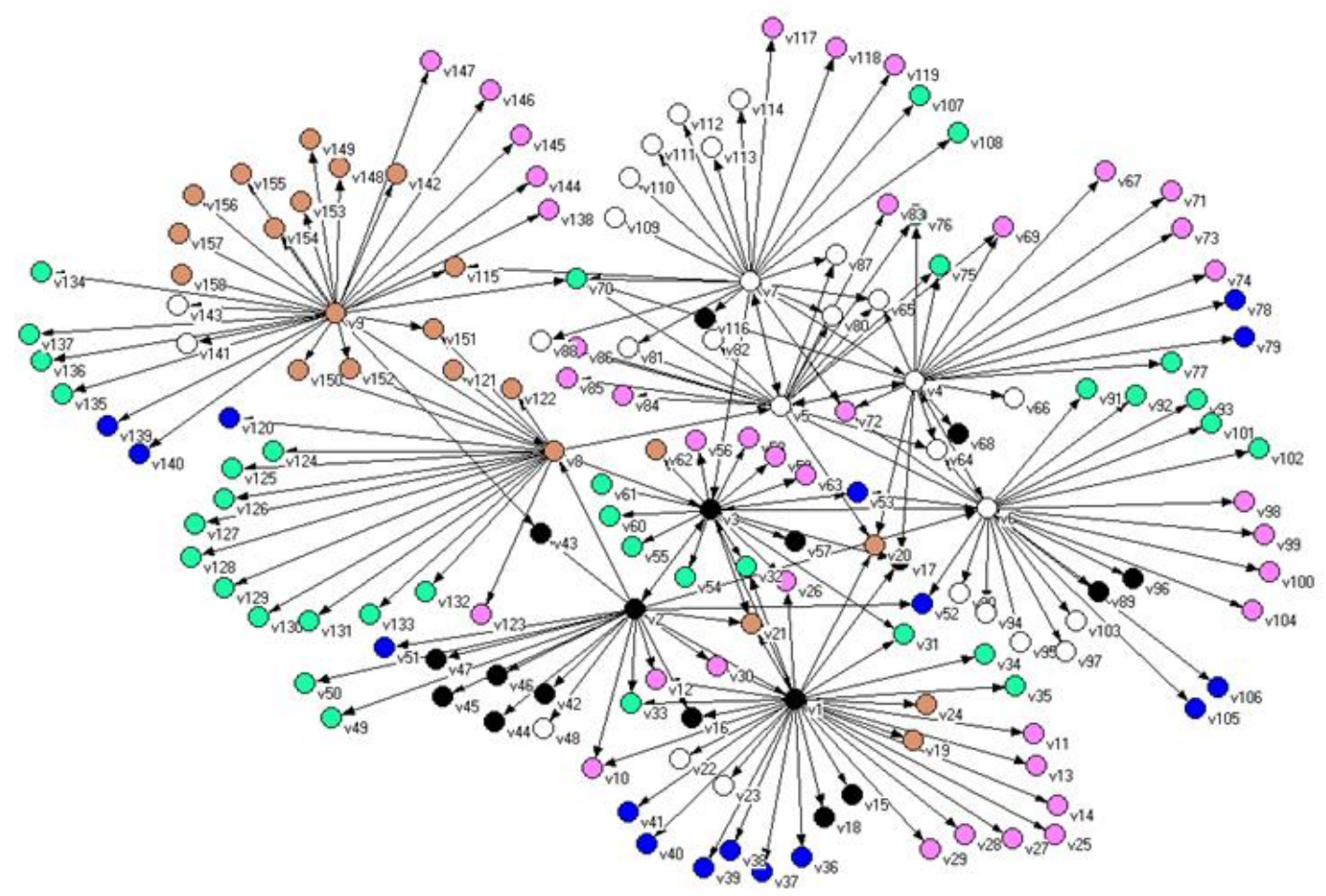

Figure 3 Interactions of FACS Divisions with Other Government Organisations

The interactions recorded by the respondents (egos and alters) across the Divisions, and other government organisations, non-government organisation, and Others (Figure 3) revealed that overall, ADHC had 32 direct ties in FACS and 42 outside FACS. Specifically, three respondents (white nodes) from ADHC had 32 direct ties within the FACS Divisions, 18 ties internally with other ADHC members, and 7 each with both CS and Housing. In contrast, 3 ADHC members had 19 direct ties with other government organisations, 14 ties with non-government organisations, and 9 with other organisations. This distribution of ties indicated greatest connections between ADHC and with other government organisations followed closely by contacts with non-government organisations. This information is important for improving integration of services; however, without further information about the reciprocity of non-FACS members, the key links or brokers between ADHC and non-FACS organisations were not available.

Overall, CS (green nodes) had 46 direct ties within FACS and 41 with divisions outside FACS. Four respondents from CS had 36 ties with other CS members, 7 had ties with $\mathrm{ADHC}$, and 3 had ties with Housing. In contrast, the CS members had 20 direct ties with government departments, 15 with non-government organisations, and 6 with other organisations. This distribution of ties indicates that CS, although highly interactive internally, had limited connections with other FACS Divisions, particularly 
Housing. CS's next highest number of connections was with government organisations followed by non-government organisations. Again, as with ADHC, it was not possible to identify the key links or brokers between CS and organisations external to FACS; however, understanding the nature of these links would be useful. From the results available, it is essential to understand the potential of service integration to further investigate the limited interactions visible in the CS division. However, the CS interaction profile might reflect the delicate and highly confidential nature of CS work and the constraints imposed on them. This highlights the importance of understanding the workplace context when pursuing opportunity/benefit of workplace management strategies. In the current study, pursuing greater interaction among divisions and integration of services would need to be examined within the work context and by considering the need for confidential consultations.

Overall, Housing had 25 direct ties within FACS and 24 outside FACS. The two respondents from Housing had 20 direct ties within Housing, 2 with ADCH, and 3 with CS. In contrast, the two Housing members had 15 ties with non-government organisations, 6 direct ties with government organisations, and 3 with other organisations. The greatest connections were found within the Housing division and with non-government organisations. Relatively limited connections emerged with any other Government Division or other organisations.

On average, the respondents from ADHC and Housing had approximately 25 ties each and respondents from CS had approximately 22 ties each. Due to the small sample size, it is not possible to make further interpretations. However, it is worth noting that an individual's social network comprises a maximum of 150 connection (Hill and Dunbar, 2003). For regular contacts (which are likely to exist for the respondents of the current study), the range varies between 6 and 20 (Dunbar and Spoors, 1995). Based on the high number of ties, which many of the respondents maintain to provide the services they offer within FACS, the capacity of individuals to maintain the necessary number of contacts should be examined. In addition, the level of relationship within those ties that is required to achieve their service delivery objectives may need to be assessed. The current study also revealed that the number of relationships individuals maintained would likely increase with position vacancies, particularly the vacancy associated with a potential structural hole. This suggests that the necessity to establish and maintain additional relationships in order to complete critical tasks may exhaust the individuals' capacity to effectively manage those relationships. 


\section{Team Climate}

The responses obtained from the respondents identified the key dimensions of the team climate within their division, such as vision, participative safety, task orientation, support for innovation, and team interactions. For the variable 'vision', this implies that there is a general understanding and appreciation of vision across teams and the division. West (1990) pointed out that the understood vision should be attainable to facilitate innovation and avoid the demotivating effect of vision not being realistically achievable. Most respondents indicated that the vision and team objectives were not realistically framed and cannot be achieved within a given period. This may suggest that the objectives underpinning the workplace vision were considered somewhat unattainable. Further investigation should ascertain whether this is actually the case, why this might be the case, and what effect this perception might have on work performance.

When asked about the participative safety, the respondents indicated that the teams the respondents operate in within their Division were generally perceived as interpersonally non-threatening or 'safe'. This perception is important, as it is likely to influence innovation quality (West 1990), increasing the likelihood of team members to make more radical suggestions that might depart from normal practice and therefore provide a richer platform of new ideas. Respondents' perceptions towards task orientation indicated a general focus on the achievement of task within a professional and respectful workplace. However there seems to be a difference of opinion in the extent of the respondents' response rates and this may be indicative of an issue associated with task orientation perceptions that may warrant further investigation.

Respondents' perceptions of support for innovation in the team climate indicated some concern about the support for innovation, particularly concerning the time available to respond to the active scrutiny of operations and to develop new ideas. Respondents' perceptions of team interactions indicated the need for innovation in achieving integration of service provision. The strong interactive operations and cooperation across the divisions would likely assist in creating integration strategies.

\section{DISCUSSION}

It is evident that the respondents' nature of work within the FACS government organisation and its divisions is very complex. The classification of these divisions into sub-divisions (for example ADHC division consisting of separate sub-divisions for ageing, disability and home care clients) adds an additional layer of structural complexity that was not obvious to the research investigators as well as to the individuals working within and across the divisions and to the client base prior to the 
study. It may be possible that efforts focused on reducing the structural complexity within the FACS government organisation would be achievable in order to enhance the transparency and increase the client navigation of services offered by the divisions associated with FACS. FACS government organisation can look into possible integration options to streamline the various divisions in order to enhance the visibility of various services offered by divisions. Noting that the work environment is by its nature intrinsically complex in terms of teams and clients management, a more simple or visible structure across divisions would assist any service integration efforts of the FACS government organisation.

The three divisions investigated here had client service positions vacant at the time of the interview, and considerable workplace changes were taking place amongst the employees working in these divisions concerning their daily job roles. This observation, in combination with the fact that the there is a limit to the capacity of individuals to functional relationships associated with the service offerings (Dunbar and Spoors, 1995) that underpin the tasks involved in providing client services, may require further investigation. It was noted that relationship capacity of many of the respondents might be exceeded or at risk of being exceeded if additional demands were placed on individuals working within and across FACS divisions.

The presence of stronger ties within divisions found in the present study indicates the strength of the team-based environment in the achievement of common goals. The results of this investigation revealed possible structural holes within the network, giving justification for further investigation of strengthening the role of key people within the network and identifying potential weaknesses and strengths that might exist within the networking process. The reason for different network pattern of relationships within and across divisions could be explored further. Expanding the scope of the study to identify and explore the relationships among key relationships and possible brokers would also be useful for improving service integration in FACS.

In terms of the team climate, respondents were generally enthusiastic about their work place. The respondents generally agreed about the vision for FACS government organisation and their specific divisions. Additionally, the participants' responses indicated that they felt at ease making participative contribution to their divisions and felt safe in the workplace. However, across all divisions, participants questioned the achievability of outcomes. This is an important workplace motivator, and this may warrant further investigation.

The perception of the capacity to achieve tasks occurring within a professional and respectful workplace was evident; however, the divergence from this perception may 
indicate an issue associated with task orientation perceptions. Additional support from the top management is essential for the implementation of new ideas.

Some evidence supported interaction behaviour across divisions. Strong interactive links have been found to be important in achieving collaboration and cooperation, and strengthening this aspect of the landscape would undoubtedly improve cross-division relationships. This research offered important insights into the mechanics, working relationships, and work environment described here as collaborative innovation landscape in a government organisation. We argue that this approach to investigating the workplace is highly contextual and requires tailoring the technique to the particular workplace being investigated. In the current study, a continued focus on structural adjustments aimed at implementing integrated case management strategies appears justified. This will likely involve identifying key teams functioning within divisions, understanding the nature of interactions in which these teams are involved, and implementing changes to optimise the potential of collaborative innovation landscape through strengthening the structure, network relationships, and team climate attributes within the workplace.

The unmet challenges in the FACS government organisation relate to the persistent problems related to mental health, disability, crime protection, and social order. Therefore, innovating the day to today operations within and across divisions of FACS would address the long-term persistent social and economic problems (Bommert, 2010). Coupled with this, the effect of the recent financial crisis is evident in the Australian government sector through dismissing many existing positions that lead to major work place changes. This has imposed severe budget constraints on the public sector, forcing the government organisations to find cost efficient ways to address the existent problems while managing the same large-scale problems.

It is evident that the existing practices within the FACS government organisation will not suffice to meet the work related challenges, and there is a need to embed a collaborative type of innovation landscape to create public value. With so many divisions operating under the FACS, it is important for the government organisation to focus on strategic type of approach rather than relying on one big change happening occasionally. Embedding strategies that focus on risk-taking and on efficient and innovative way of using available funds and increasing the potential for team climate within and across the various divisions of FACS would automatically provide solutions to the existing large-scale social and economic problems. 


\section{CONCLUSION}

This study describes the applicability of integrated theoretical frameworks for exploring the utility of a collaborative innovation landscape within FACS government organisation by conducting qualitative in-depth interviews with individuals working across various divisions of FACS. The presence of a collaborative type of innovation landscape seems to be limited within the Australian public sector due to challenges associated with the persistent social and economic problems. Embedding measures to enhance a collaborative innovation landscape in the government organisations is likely to promote many serial innovations within the public sector to find solutions to unmet large-scale social and economic problems.

The present study is limited as it is based on only one government organisation FACS and its divisions. Therefore, the results obtained from this study are highly contextualised and cannot be generalised to other government organisations. Massive restructuring and work place changes happening within the public sector at the time of this research may compound the results obtained from this study. Future research need to focus on identifying favourable and unfavourable factors within the government organisations to promote the collaborative innovation landscape. Responses need to be gathered from individuals from different management levels in order to identify whether the perceptions held by the top, middle and lower management converge or diverge

\section{REFERENCES}

Acuña, S. T., Gomez, M. and Juristo, N. (2008). Towards understanding the relationship between team climate and software quality - a quasi-experimental study. Empir Software Eng, 13(4), 401-434. http://dx.doi.org/10.1007/s10664-008-9074-8/

Agranoff, R. (2007). Managing within Networks: Adding Value to Public Organisations. Washington DC: Georgetown University Press.

Armbruster, H., Bikfalvi, A., Kinkel, S. \& Lay, G. (2008). Organisational innovation: The challenge of measuring non-technical innovation in large-scale surveys. Technovation, 28(10), 644-657. http://dx.doi.org/10.1016/ j.technovation.2008.03.003

Anderson, N. \& West, M. (1998). Measuring climate for work group innovation: Development and validation of the team climate inventory. Journal of Organisational Behaviour, 19(3), 235-258. http://dx.doi.org/10.1002/(SICI)1099-1379(199805)19:3\%3C235::AID-JOB837 \%3E3.0.CO;2-C 
Baer, M. and Frese, M. (2003). Innovation is not enough: Climates for initiative and psychological safety, process innovation, and firm performance. Journal of Organisational Behaviour, 24(1), 45-68. http://dx.doi.org/10.1002/job.179

Battisti, G. \& Stoneman, P. (2010). How innovative are UK firms? Evidence from the fouth UK community innovation survey on synergies between technological and organisational innovations. British Journal of Management, 21(1), 187-206. http://dx.doi.org/10.1111/j.1467-8551.2009.00629.x

Beck, K., Beedle, M., Cockburn, A., Cunnigham, W. \& Fowler, M. (2001). The agile Manifesto. Retrieved March $10^{\text {th }} 2014$ from www.agilemanifesto.org

Bell, S. T. (2007). Deep-level composition variables as predictors of team performance: A meta-analysis. Journal of Applied Psychology, 92(3), 595-615. http://dx.doi.org/10.1037/0021-9010.92.3.595

Boehm, B. W., Abts, C., Brown, W. A., Chulani, S., Clark, B. K., Horowitz, E., Madachy, R., Reifer, D. J. \& Steece, B. (2000). Software cost estimation with COCOMO II. Prentice-Hall, Upper Saddle River, NJ.

Bommert, B. (2010). Collaborative innovation in the public sector. International Public Management Review, 11 (1), 15-33.

Burke, C. S., Stagl, K. C., Salas, E., Pierce, L. \& Kendall, D. (2006). Understanding team adaptation: A conceptual analysis and model. Journal of Applied Psychology, 91, 1189-1207. http://dx.doi.org/10.1037/0021-9010.91.6.1189

Camison. C. \& Villar-Lopez, A. (2014). Organisational innovation as an enabler of technological innovation capabilities and firm performance. Journal of Business Research, 67(1), 2891-2902. http://dx.doi.org/10.1016/j.jbusres.2012.06.004

Choi, J. N. \& Chang, J. Y. (2009). Innovation implementation in the public sector: An integration of institutional and collective dynamics. Journal of Applied Psychology, 94(1), 245-253. http://dx.doi.org/10.1037/a0012994

Choi, J. N. (2007). Change-oriented organisational citizenship behaviour: Effects of work environment characteristics and intervening psychological processes. Journal of Organisational Behaviour, 28(4), 467-484. http://dx.doi.org/10.1002/job.433

Choi, J. N., Anderson, T. A. \& Veillette, A. (2009). Contextual inhibitors of employee creativity in organisations: The insulating role of creative ability. Group and Organisation Management, $34(3)$, 330-357. http://dx.doi.org/10.1177/1059601108329811 
Cladwell, D. F. \& O'Reilly, C. A. (2003). The determinants of team-based innovation in organisations: The role of social influence. Small Group Research, 34(4), 497-517. http://dx.doi.org/10.1177/1046496403254395

Cotton, P. \& Hart, P. M. (2003). Occupational wellbeing and performance: A review of organisational health research. Australian Psychologist, 38 (2), 118-127. http://dx.doi.org/10.1080/00050060310001707117

Cotton, P. (2004). Developing an optimal organisation climate: Towards Australia's safest workplaces II conference paper, Canberra.

Crossan, M. M. \& Apaydin, M. (2010). A multi-dimensional framework of organisational innovation: A systematic review of the literature. Journal of Management Studies, $\quad 47 \quad$ (6), $1154-1191$. http://dx.doi.org/10.1111/j.1467-6486.2009.00880.x

Damanpour, F. \& Aravind, D. (2012). Managerial innovation: Conceptions, processes, and antecedents. Management and Organisation Review, 8(2), 423-454. http://dx.doi.org/10.1111/j.1740-8784.2011.00233.x.

Dunbar, R.I.M. \& Spoors, M. (1995). Social networks, support cliques, and kinship. Human Nature, 6(3), 273-291. http://dx.doi.org/10.1007/BF02734142

Edmondson, A. (1999). Psychological safety and learning behaviour in work teams. Administrative Science Quarterly, 44(2), 350-383. http://dx.doi.org/10.2307/2666999

Eggers, W. D. \& Singh, K.S. (2009). The Public Innovator's Playbook: Nurturing Bold Ideas in Government. Deloitte Research.

Hackman, J. R. (1987). The design of work teams In Lorsch. J. W. (Ed.), Handbook of Organisational Behaviour (p. 315-342), Engelwood Cliffs. NJ: Prentice-Hall.

Hamel, G. (2006). The why, what and how of management innovation. Harvard Business Review, 84 (2), 72-84.

Hansen, T. \& Levine, J. M. (2009). Newcomers as change agents: Effects of newcomers' behavioural style and teams' performance optimism. Social Influence, 4, 46-61. http://dx.doi.org/10.1080/15534510802280827

Harris, M. \& Albury, D. (2009). Why Radical Innovation is needed for the Recession and Beyond: The Innovation Imperative. NESTA Discussion Paper, March.

Heinrich, C. L., Lynn, L. E. \& Milward, B. (2009). A state of agents? Sharpening the debate and evidence over the extent and impact of the transformation of governance. Journal of Public Administration Research and Theory, 20(1), 3-19. http://dx.doi.org/10.1093/jopart/mup032 
Hill, R.A. \& Dunbar, R.I.M. (2003). Social network size in humans. Human Nature, 14(1), 53-72. http://dx.doi.org/10.1007/s12110-003-1016-y

Howell, J. M. \& Shea, C. M. (2006). Effects of champion behaviour, team potency, and external communication activities on predicting team performance. Group Organisation

Management, $31(2)$,

180-211. http://dx.doi.org/10.1177/1059601104273067

Hulsheger, U. R., Anderson, N. \& Salgado, J. F. (2009). Team-level predictors of innovation at work: A comprehensive meta-analysis spanning three decades of research. Journal of Applied Psychology, 94(5), 1128-1145. http://dx.doi.org/10.1037/a0015978

Humphrey, W. S. \& Konrad, M. D. (2005). Motivation and process improvement In Acuna, S. T. and Juristo, N. (Ed.), Software Process Modelling, Springer, New York.

Ilgen, D. R., Hollenbeck, J. R., Johnson, M. \& Jundt, D. (2005). Teams in organisations: From input-process-output models to IMOI models. Annual Review of Psychology, 56, 517-543. http://dx.doi.or/10.1146/annurev.psych.56.091103.070250

Jimenez-Jimenez, D. \& Sanz-Valle, R. (2011). Innovation, organisational learning, and performance. Journal of Business Research, 64(4), 408-417. http://dx.doi.org/10.1016/j.jbusres.2010.09.010

King, N., Anderson, N. \& West, M. A. (1991). Organisational innovation: A case study into perceptions and processes. Work and Stress, 5, 331-339.

Koppenjan, J. \& Klinjn, E. H. (2004). Managing Uncertainties in Networks. London, England: Routledge.

Liao, S.H. \& Chi-Chuan, W. (2010). System perspective of knowledge management, organisational learning, and organisational innovation. Expert Systems with Applications, 37 (2), 1096-1103. http://dx.doi.org/10.1016/j.eswa.2009.06.109

Mathieu, J. E., Maynard, M. T., Rapp, T. \& Gilson, L. (2008). Team effectiveness 1997-2007: A review of recent advancements and a glimpse into the future. Journal of Management, 34(3), 410-477. http://dx.doi.org/10.1177/0149206308316061

Nambisan, S. (2008). Transforming Government through Collaborative Innovation. IBM Centre for the Business of Government.

NSW Government Directory (2014). Retrieved $8^{\text {th }}$ March 2014 from www.directory.nsw.gov.au/showorgunit 
NSW Government Family and Community Services (2014), Retrieved $10^{\text {th }}$ November 2013 from www.facs.nsw.gov.au

OECD (2005). The measurement of scientific and technological activities. Oslo Manual. Guidelines for collecting and interpreting innovation date $\left(3^{\text {rd }}\right.$ ed.). Paris: OECD Eurostat.

Ortega, M. J. R. (2010). Competitive strategies and firm performance: Technological capabilities' moderating roles. Journal of Business Research,63(12), 1273-1281. http://dx.doi.org/ 10.1016/j.jbusres.2009.09.007.

Reichers, A. E. \& Schneider, B. (1990). Cimate and culture: An evolution of constructs In Schneider, B. (Ed.), Organisational Climate and Culture, Jossey-Bass, San Franscisco.

Rickards, T., Chen, M. H. \& Moger, S. (2001). Development of a self-report instrument for exploring team factor, leadership and performance relationships. British Journal of Management, 12(3), 243-250. http://dx.doi.org/10.1111/1467-8551.00197

Scott, J. (2000). Social Network Analysis. A Handbook. London.

Shalley, C. E., Zhou, J. \& Oldham, G. R. (2004). The effects of personal and contextual characteristics on creativity: Where should we go from here? Journal of Management, 30(6), 933-958. http://dx.doi.org/10.1016/j.jm.2004.06.007

Somech, A. (2006). The effects of leadership style and team process on performance and innovation in functionally heterogeneous teams. Journal of Management, 32(1), 132-157. http://dx.doi.org/10.1177/0149206305277799

Sorensen, E. \& Torfing, J. (2011). Enhancing collaborative innovation in a public sector. Administration \& Society, 43(8), 842-868. http://dx.doi.org/10.1177/0095399711418768

Sorensen, E. \& Torfing, J. (2012). Collaborative innovation in the public sector. The Innovation Journal: The Public Sector Innovation Journal, 17 (1), 1-14.

Strating, M. M. H. \& Nieboer, A. P. (2009). Psychometric test of the team climate inventory - short version investigated in Dutch quality improvement teams. BMC Health Services Research, 9 (126), 1-7.

Tiwana, A. \& McLean, E. R. (2005). Expertise integration and creativity in information systems development. Journal of Management Information Systems, 22(1), 13-43. http://dx.doi.org/10.1080/07421222.2003.11045836

Tjosvold, D., Tang, M. M. L. \& West, M. (2004). Reflexivity for team innovation in China: The Contribution of Goal Interdependence. Group \& Organisation Management, 29(5), 540-559. http://dx.doi.org/10.1177/1059601103254911 
Walker, R. M., Damanpour, F. \& Devece, C. A. (2010). Management innovation and organisational performance: The mediating effect of performance management. Journal of Public Administration Research and Theory, 21(3), 367-386. http://dx.doi.org/10.1093/jopart/muq043

West, M. A. \& Anderson, N. R. (1996). Innovation in top management teams. Journal of Applied Psychology, 81(6), 680-693. http://dx.doi.org/10.1037/0021-9010.81.6.680

West, M. A. (1990). The social psychology of innovation in groups In West. M. A. and Farr, J. L. (Ed.), Innovation and Creativity Work. Wiley, Chichester.

West, M. A. (2002). Sparkling fountains or stagnant ponds: An integrative model of creativity and innovation implementation in work groups. Applied Psychology: An International Review, 51(3), 355-424. http://dx.doi.org/10.1111/1464-0597.00951

Woodman, R. W., Sawyer, J. E. \& Griffin, R. W. (1993). Toward a theory of organisational creativity. Academy of Management Review, 18(2), 293-321. http://dx.doi.org/10.5465/AMR.1993.3997517

Yang, C. C., Marlow, P. B. \& Lu, C. S. (2009). Assessing resources, logistics service capabilities, innovation capabilities and the performance of container shipping. International Journal of Production Economics, 122(1), 4-20. http://dx.doi.org/10.1016/j.ijpe.2009.03.016 
